\title{
Comparison of the long term prognostic value of peak exercise oxygen pulse and peak oxygen uptake in patients with chronic heart failure
}

\author{
A Cohen-Solal, P Barnier, F Pessione, P Seknadji, D Logeart, T Laperche, R Gourgon
}

\begin{abstract}
Objective-To evaluate the ratio of peak oxygen consumption to peak heart rate (peak oxygen pulse) as a predictor of long term prognosis in chronic heart failure. Patients and setting-178 consecutive heart failure patients recruited to the cardiology department of a tertiary referral centre between 1986 and 1993.

Design-Bicycle ergometry with measurement of respiratory exchange. Mean (SD) follow up was 32 (25) months.

Results-Patients who died had a lower peak oxygen consumption (16.0 (5.5) $v$ $18.0(5.5) \mathrm{ml} / \mathrm{min} / \mathrm{kg}, \mathrm{p}=0.05)$, lower indexed peak oxygen consumption (52 (14) $v$ $60(16) \%, p=0.006)$ but similar peak oxygen pulse $(8.4(2.6) \quad v \quad 8.4(3.0) \mathrm{ml} / \mathrm{beat}$, NS). The following variables were associated with a good long term prognosis: New York Heart Association class II, nonischaemic heart failure, peak oxygen consumption $\geqslant 17 \mathrm{ml} / \mathrm{min} / \mathrm{kg}$, indexed peak oxygen consumption $>63 \%$. Peak oxygen pulse did not have predictive value. Only indexed peak oxygen consumption remained an independent predictor of survival in multivariate analysis.

Conclusions-Peak oxygen pulse has lower prognostic value than peak oxygen consumption, especially when the latter is indexed to predicted values.

(Heart 1997;78:572-576)
\end{abstract}

Keywords: prognosis; oxygen consumption; oxygen pulse; exercise; heart failure

Cardiologie, Hôpital

Beaujon, Clichy,

France

A Cohen-Solal

P Barnier

P Seknadji

D Logeart

T Laperche

R Gourgon

Département

d'Epidémiologie,

Hôpital Beaujon,

Clichy, France

F Pessione

Correspondence to:

$\operatorname{Pr}$ A Cohen-Solal, Service de

Cardiologie-Hôpital

Beaujon, 100 Boulevard du

General Leclerc, 92110

Clichy, France.

Accepted for publication

9 September 1997

Chronic heart failure carries a mortality rate of $10-50 \%$ at one year, depending on severity. ${ }^{1-3}$ Peak oxygen consumption during graded exercise has emerged in recent years as one of the most important independent factors in the prognosis of chronic heart failure, ${ }^{4-12}$ and is now one of the main elements guiding the decision to carry out heart transplantation. ${ }^{13}$ Unfortunately, follow up has generally been limited, ruling out analyses of long term survival. Moreover, peak oxygen consumption has generally been expressed in $\mathrm{ml} / \mathrm{min} / \mathrm{kg},{ }^{14}$ and the use of indexed peak oxygen consumption, which also takes account of both age and sex, remains under debate. ${ }^{15}{ }^{16}$ Finally, the peak oxygen pulse (the ratio of peak oxygen consumption to peak heart rate), that is, the product of stroke volume multiplied by the arteriovenous oxygen difference-which seems to be more dependent than peak oxygen consumption on cardiac pump function reserve (as it does not incorporate heart rate reserve) - has never been evaluated.

The aim of this study was thus to determine the prognostic value of peak oxygen pulse and peak oxygen uptake in the long term in a large population of consecutively investigated patients with heart failure.

\section{Methods}

PATIENTS

Since 1985, all patients referred to our cardiology department with heart failure have performed a maximum graded exercise test. Hospital inpatients do the exercise test on discharge. We excluded from this study those patients whose heart failure was predominantly due to severe valve disease and the few who exercised on a treadmill. We carefully reviewed the raw data and excluded patients who stopped exercising for reasons other than dyspnoea or fatigue (poor motivation, arrhythmias, myocardial ischaemia, sudden drop in blood pressure, respiratory insufficiency, and so on). Heart failure was diagnosed on the basis of the usual clinical criteria - that is, exertional dyspnoea, peripheral oedema, or episodes of pulmonary congestion-together with evidence of left ventricular systolic dysfunction on echocardiography, radionuclide ventriculography, or haemodynamic studies. Most patients were receiving angiotensin converting enzyme inhibitors plus diuretics.

There were 183 consecutive patients who were considered for analysis on this basis. Five were excluded because data were incomplete.
The study cohort thus comprised 178 patients, recruited between 1986 and 1993.

\section{EXERCISE TESTS}

Exercise tests were performed on a bicycle. Ongoing treatments were not stopped before the test. We used upright graded exercise with workload increments of 10 watts per minute after an initial workload of 20 watts. We always encouraged patients to exercise until exhaustion. Respiratory gases were analysed on a Medical Graphics Corporation system (St Paul, Minnesota, USA). The equipment was calibrated with a standard gas mixture before each test.

Oxygen consumption $\left(\dot{\mathrm{V}}_{2}\right)$, carbon dioxide production, minute ventilation, and the respibreath by breath basis and the results were ratory exchange ratio were measured on a 
averaged across 15 second intervals. All patients reached their ventilatory threshold, determined by use of the combination of multiple graphs ${ }^{17}$; all but three had a respiratory exchange ratio of $>1.0$ (those three patients had a ratio of 0.98 or 0.99 and attained more than $90 \%$ of maximum predicted heart rate at peak exercise).

Peak oxygen consumption was defined as the highest averaged oxygen consumption value during the test and was expressed in $\mathrm{ml} / \mathrm{min} / \mathrm{kg}$.

The peak oxygen pulse was defined as peak oxygen consumption divided by peak heart rate and was expressed in $\mathrm{ml}$ per beat. The indexed peak oxygen consumption (\%) was calculated as peak oxygen consumption divided by maximum predicted oxygen consumption, using the values reported by Wasserman et al. ${ }^{18}$

OTHER PROGNOSTIC VARIABLES

The other candidate prognostic variables were age, New York Heart Association (NYHA) functional class, ${ }^{19}$ aetiology of heart failure, and left ventricular ejection fraction. Aetiologies were separated into ischaemic and nonischaemic heart failure. Ischaemic heart failure was defined by the presence of severe coronary artery lesions, and a history of myocardial infarction or akinesia on cross sectional echocardiography. Heart failure of other causes (alcoholic, toxic, idiopathic, etc) was defined as non-ischaemic. Left ventricular ejection fraction was measured in 158 patients by means of radionuclide or contrast ventriculography $(\mathrm{n}=144)$ or echocardiography $(\mathrm{n}=14)$, using the Teichholz formula.

\section{FOLLOW UP}

Minimum follow up was six months. Outcome was assessed either directly (when the patient's physician was a member of the medical staff), or by contacting the patient's practitioner by letter or telephone. The date and cause of death was documented in every case except for five patients, for whom analysis was censored at the last date when they were known to be alive. All 35 deaths were cardiac deaths. Twenty three patients underwent cardiac transplantation during follow up. As this procedure may alter prognosis, two methods of analysing outcome were used: first, censoring patients who underwent cardiac transplantation at the time of intervention (considering them alive at this time); second, considering transplantation as death, as the separation between urgent and non-urgent transplantation is disputable.

STATISTICAL ANALYSIS

We used the SAS statistical package (SAS Institute, Cary, North Carolina). Numerical values are expressed as mean (SD). Differences between the means of groups was made by the Student $t$ test. Proportions were compared using the $\chi^{2}$ test. $\mathrm{p}$ values of 0.05 or less are considered significant.

Kaplan-Meier cumulative mortality curves were plotted to the end of follow up to describe trends in mortality over time in each of the risk categories. ${ }^{20}$ Survival curves were compared by the log-rank test.
Table 1 Baseline characteristics

\begin{tabular}{|c|c|}
\hline Mean (SD) age (years) & 52 (11) \\
\hline Number of men (\%) & $161 \quad(90)$ \\
\hline Number of women (\%) & $17 \quad(10)$ \\
\hline \multicolumn{2}{|l|}{ Number in NYHA class (\%) } \\
\hline II & $76 \quad(43)$ \\
\hline III & $81 \quad(45)$ \\
\hline $\mathrm{V}$ & $21 \quad(15)$ \\
\hline \multicolumn{2}{|l|}{ Aetiology (n (\%)) } \\
\hline Ischaemic & $75 \quad(42)$ \\
\hline Non-ischaemic & $103(58)$ \\
\hline Mean (SD) ejection fraction (\%) & $25 \quad(11)$ \\
\hline Mean (SD) peak $\dot{\mathrm{VO}}_{2}(\mathrm{ml} / \mathrm{kg} / \mathrm{min})$ & $17.6(5.6)$ \\
\hline $\begin{array}{l}\text { Mean (SD) indexed peak } \dot{\mathrm{VO}}_{2} \\
\quad(\% \text { predicted values })\end{array}$ & $58 \quad(16)$ \\
\hline Mean (SD) peak $\mathrm{O}_{2}$ pulse $(\mathrm{ml})$ & $8.7(3.0)$ \\
\hline
\end{tabular}

NYHA, New York Heart Association; $\dot{\mathrm{VO}}_{2}$, oxygen consumption.

Relative risk ratio with $95 \%$ confidence intervals (CI), described by the relative hazard constant, $\exp ^{(\beta)}$ ( $\beta$ being the regression coefficient), were calculated by a Cox proportional hazards method $^{21}$ for the following variables: age, NYHA functional class, aetiology, left ventricular ejection fraction, peak oxygen consumption, peak oxygen pulse, and indexed peak oxygen consumption. For continuous variables, when the statistical test was significant, we looked at the cut off value that discriminated best between survivors and nonsurvivors. Variables predictive of survival by univariate analysis $(p<0.05)$ were then entered in a Cox proportional hazards regression model to determine their significance as independent predictors of survival in multivariate analysis. We thus used three models - peak oxygen consumption, indexed peak oxygen consumption, or peak oxygen pulse-adjusted for the other covariates. If one or more of the variables was unavailable, the patient was excluded from the analysis.

\section{Results}

CLINICAL CHARACTERISTICS

Clinical details are given in table 1 . There were 161 men (90\%) and 17 women (10\%). Mean age was 52 (11) years. The aetiology of heart failure was ischaemic in 75 cases $(42 \%)$ and non-ischaemic in 103 cases (58\%). At baseline, 76 patients $(43 \%)$ were in NYHA functional class II, $81(45 \%)$ in class III, and $21(12 \%)$ in class IV. The mean left ventricular ejection fraction was $25(11) \%$. All but six patients had sinus rhythm.

Mean peak oxygen consumption was $17.6(5.6) \mathrm{ml} / \mathrm{min} / \mathrm{kg}$ in the whole population (range $6.5-39 \mathrm{ml} / \mathrm{min} / \mathrm{kg}$ ). Fifty patients were in class A, 59 in class B, 59 in class C, and 10 in class D, according to the usual classification. ${ }^{14}$ Mean indexed peak oxygen consumption was $58(16) \%$. The mean peak oxygen pulse was $8.7(3.0) \mathrm{ml} / \mathrm{beat}$.

\section{MORTALITY}

Mean follow up was 32 (25) months. Mortality rates at 1,2 , and 5 years were $13 \%, 19 \%$, and $35 \%$, respectively.

There was no difference between survivors and non-survivors as regards sex or age (table 2 ). The discriminatory value of the NYHA functional class was not statistically significant $(\mathrm{p}=0.1)$; it poor remained even when patients 
Table 2 Comparison of survivors and non-survivors

\begin{tabular}{|c|c|c|c|}
\hline & Alive & Dead & $p$ \\
\hline Number & 143 & 35 & \\
\hline Mean (SD) age (years) & $51 \quad(11)$ & $53 \quad(11)$ & NS \\
\hline Number in NYHA class & & & NS \\
\hline II & 66 & 10 & \\
\hline III & 60 & 21 & \\
\hline IV & 17 & 4 & \\
\hline Aetiology (n) & & & 0.05 \\
\hline Ischaemic & 55 & 20 & \\
\hline Non-ischaemic & 88 & 15 & \\
\hline Mean (SD) ejection fraction (\%) & $26 \quad(11)$ & $23 \quad(13)$ & NS \\
\hline Mean (SD) peak $\mathrm{VO}_{2}(\mathrm{ml} / \mathrm{kg} / \mathrm{min})$ & $18.0(5.5)$ & $16.0(5.5)$ & 0.05 \\
\hline $\begin{array}{l}\text { Mean (SD) indexed peak } \mathrm{VO}_{2} \\
\text { (\% predicted values) }\end{array}$ & $60 \quad(16)$ & $52 \quad(14)$ & 0.006 \\
\hline Mean (SD) peak $\mathrm{O}_{2}$ pulse $(\mathrm{ml})$ & $8.8(3.0)$ & $8.4(2.6)$ & 0.1 \\
\hline
\end{tabular}

NYHA, New York Heart Association; $\dot{\mathrm{VO}}_{2}$, oxygen consumption.

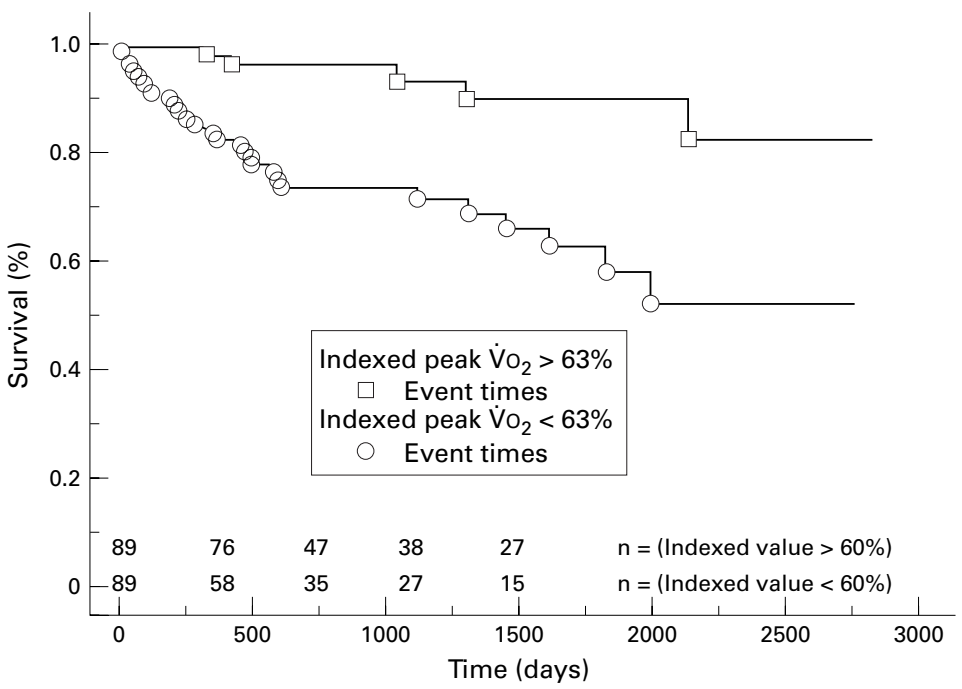

Figure 1 Probability of survival according to the baseline indexed peak oxygen consumption $\left(\dot{\mathrm{V} O} \mathrm{O}_{2}\right)$, expressed as a percentage of predicted values, greater or lower than $63 \%$. Curves were constructed with the Kaplan-Meier method ( $p=0.0003)$.

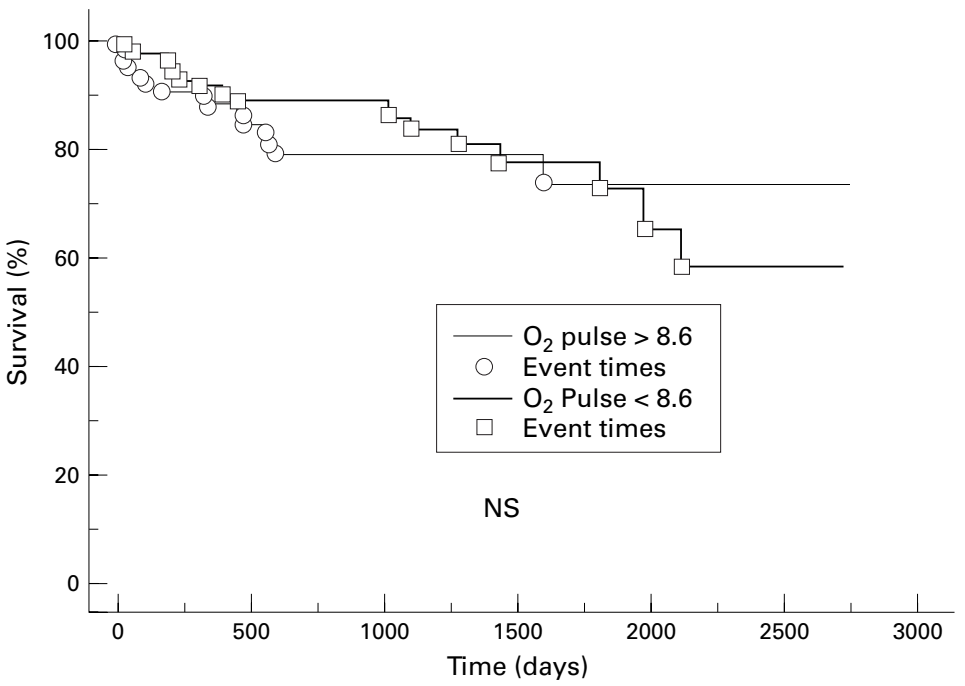

Figure 2 Probability of survival according to baseline peak oxygen pulse (peak $\mathrm{O}_{2}$ pulse). The cut off value was $8.6 \mathrm{ml}$. Curves were constructed with the Kaplan-Meier method $(p=N S)$.

were stratified into two groups only (class II or classes III-IV) ( $p=0.05)$. Patients with ischaemic heart failure had a worse prognosis than those with non-ischaemic heart failure $(\mathrm{p}=0.05)$. As in most recent studies, left ventricular ejection fraction did not differ between survivors and non-survivors (26(11) v
Table 3 Survival curves

\begin{tabular}{|c|c|}
\hline Prognostic factor (cut off values) & $\chi^{2}(p)$ \\
\hline $\begin{array}{l}\text { Indexed peak } \dot{\mathrm{V}} \mathrm{O}_{2}(63 \%) \\
\text { Peak } \dot{\mathrm{V}} \mathrm{O}_{2}(17 \mathrm{ml} / \mathrm{min} / \mathrm{kg}) \\
\text { Peak } \mathrm{O}_{2} \text { pulse }(8.6 \mathrm{ml} / \text { beat }) \\
\text { Aetiology (ischaemic/ non-ischaemic) } \\
\text { NYHA functional (class II/III-IV) } \\
\text { Ejection fraction }(23 \%)\end{array}$ & $\begin{array}{cl}13.3 & (0.0003) \\
9.2 & (0.002) \\
0.07 & (0.79) \\
4.6 & (0.03) \\
4.8 & (0.03) \\
3.4 & (0.06)\end{array}$ \\
\hline \multicolumn{2}{|c|}{$\begin{array}{l}\chi^{2} \text { Values of the log-rank test (transplantation censored). } \\
\mathrm{VO}_{2} \text {, oxygen consumption; NYHA, New York Heart Associ- } \\
\text { ation. }\end{array}$} \\
\hline
\end{tabular}
lower peak oxygen consumption $(16.0$ (5.5) $v$ $18.0(5.5) \mathrm{ml} / \mathrm{min} / \mathrm{kg}, \mathrm{p}=0.05)$ and lower indexed peak oxygen consumption (52(14) $v$ $60(16) \%, p=0.006)$ than those who survived. Sixty two per cent of the patients who died had a peak oxygen consumption $\geqslant 14 \mathrm{ml} / \mathrm{min} / \mathrm{kg}$.

The peak oxygen pulse did not differ between the two groups $(p=0.1)$.

\section{Survival curves}

Ischaemic heart failure carried a worse prognosis than non-ischaemic heart failure, as did functional class III-IV compared with functional class II (both $p=0.03$ ). An ejection fraction cut off of $23 \%$ had a poor, not significant, discriminatory value $(\mathrm{p}=0.06)$ in this population. Peak oxygen consumption $(\mathrm{p}=0.002)$ and indexed peak oxygen consumption $(p=0.0003)$ were highly predictive of survival, with cut off values of $17 \mathrm{ml} / \mathrm{min} / \mathrm{kg}$ and $63 \%$ respectively (fig 1 ) (table 3 ). The peak oxygen pulse (cut off value $8.6 \mathrm{ml} / \mathrm{beat}$ ) did not discriminate between survivors and nonsurvivors (fig 2).

Univariate and multivariate analysis

Univariate analyses of covariates as continuous variables yielded significant results only for peak oxygen consumption (Wald $\chi^{2}=4.5$, $\mathrm{p}=0.03)$ and indexed peak oxygen consumption (Wald $\chi^{2}=10.5, \mathrm{p}=0.001$ ) (table 4). Risk ratio were 1.07 (95\% CI 1.01 to 1.13 ) for peak oxygen consumption $(\mathrm{ml} / \mathrm{min} / \mathrm{kg})$ and 1.04 (95\% CI 1.02 to 1.06 ) for indexed peak oxygen consumption (per cent of the predicted values). Considering the covariates as categorical variables, relative risk were 2.96 (95\% CI 1.47 to $6.17, \mathrm{p}=0.004)$ for peak oxygen consumption (cut off value $17 \mathrm{ml} / \mathrm{min} / \mathrm{kg}$ ), $4.91(95 \%$ CI 1.90 to $12.67, \mathrm{p}=0.001$ ) for indexed peak oxygen consumption (cut off value $63 \%$ ), and only 1.28 (95\% CI 0.66 to 2.50 , NS) for peak oxygen pulse (cut off value $8.6 \mathrm{ml} /$ beat).

Functional class, aetiology, and one of the three exercise variables (peak oxygen consumption, indexed peak oxygen consumption, or peak oxygen pulse) were each entered in one Cox model to determine the independent predictive value of each of the exercise derived variables. Peak oxygen consumption was predictive of survival (cut off value $17 \mathrm{ml} / \mathrm{min} / \mathrm{kg}$ ) $(p=0.03)$. The peak oxygen pulse did not have independent predictive value $(p=0.3)$. Indexed peak oxygen consumption $(p=0.006)$ was the best independent predictor of survival. 
Table 4 Univariate and multivariate predictive value of survival of exercise derived variables

\begin{tabular}{lll}
\hline Variable & $\begin{array}{l}\text { Univariate analysis risk ratio } \\
\text { (95\% CI) }\end{array}$ & $\begin{array}{l}\text { Multivariate analysis risk ratio } \\
\text { (95\% CI) }\end{array}$ \\
\hline Peak $\dot{\mathrm{V} O} \mathrm{O}_{2}$ & $2.96(1.42$ to 6.17$)(\mathrm{p}=0.004)$ & $2.27(1.06$ to 4.87$)(\mathrm{p}=0.03)$ \\
Indexed peak $\dot{\mathrm{VO}}_{2}$ & $4.91(1.90$ to 12.67$)(\mathrm{p}=0.001)$ & $3.90(1.49$ to 10.25$)(\mathrm{p}=0.006)$ \\
Peak $\mathrm{O}_{2}$ pulse & $1.28(0.66$ to 2.50$)(\mathrm{NS})$ & $1.05(0.53$ to 2.07$)(\mathrm{NS})$ \\
\hline
\end{tabular}

The risk ratio and their confidence interval were calculated by a Cox proportional hazards regression model in which each of the three variables was the only covariate (univariate analysis) or was entered with the other variables that were predictive of survival $(\mathrm{p}<0.05)$ by univariate analysis-aetiology and NYHA class (multivariate analysis). Cut off values as in table 3 .

$\mathrm{CI}$, confidence interval, $\dot{\mathrm{VO}}_{2}$, oxygen consumption.

Table 5 Survival curves

\begin{tabular}{ll}
\hline Prognostic factor & $\chi^{2}(p)$ \\
\hline Indexed peak $\dot{\mathrm{VO}}_{2}$ & $17.5(<0.0001)$ \\
Peak $\mathrm{VO}_{2}$ & $14.0(0.0002)$ \\
Peak $\mathrm{O}_{2}$ pulse & $1.8(0.2)$ \\
Aetiology & $6.0(0.01)$ \\
NYHA functional class & $6.8(0.009)$ \\
Ejection fraction & $5.7(0.01)$
\end{tabular}

$\chi^{2}$ Values of the log-rank test when transplantation was considered as death.

$\dot{\mathrm{VO}}_{2}$, oxygen consumption; NYHA, New York Heart Association.

Other analyses

When equating cardiac transplantation with death, the number of events increased and aetiology, NYHA class, peak oxygen consumption, and indexed peak oxygen consumption, but not peak oxygen pulse, had prognostic value (table 5). Finally, excluding the six patients in atrial fibrillation did not increase the prognostic value of the peak oxygen pulse.

\section{Discussion}

This study is one of the largest conducted in a single centre ${ }^{75_{22}}$ to have assessed the prognostic value of peak oxygen consumption in patients with heart failure, and has the longest mean follow up (32 months) so far reported, allowing long term survival to be assessed. The main findings were that indexed peak oxygen consumption was the best independent predictor of long term survival in these patients with heart failure, whereas the prognostic value of the peak oxygen pulse was low.

In the last 10 years, various investigators have tried to assess the prognostic value of peak oxygen consumption measured during graded exercise in patients with heart failure. All except one $\mathrm{e}^{8}$ showed its considerable predictive value for outcome..$^{4-12} 1516$ 23-25 However, because of methodological differences (differences in cohort size, follow up, analysis of outcome after transplantation, or severity of heart failure at entry in the study), the cut off value that best predicts outcome has varied considerably from one study to the next. The fact that our cut off values are greater than those reported in most previous studies 46926 is probably due to the broad spectrum of heart failure in our study, in which both hospital inpatients ambulatory patients were enrolled (one year mortality was $13 \%$, a figure similar to those recently reported in the enalapril arms of the SOLVD ${ }^{2}$ and V-HeFT $\mathrm{II}^{3}$ trials), or to our long duration of follow up. Clearly, the longer the follow up, the higher the peak oxygen consumption cut off value. The duration of follow up in our study in the longest so far reported. In Mancini's study, from which is derived the "gold number" of $14 \mathrm{ml} / \mathrm{min} / \mathrm{kg}$, ${ }^{9}$ all patients were referred for heart transplantation and duration of follow up was only 11 months on average.

Age, sex, and previous training influence predicted maximum oxygen consumption. Various tables have been proposed to predict the actual maximum exercise induced oxygen consumption, ${ }^{18}{ }^{27}$ but their validity in deconditioned patients with heart failure is open to question. One patient out of six was classified differently according to one or other classification. Univariate and multivariate analyses showed that indexed peak oxygen consumption was more predictive than non-indexed values, in accordance with two recently reported studies $^{15}{ }^{16}$; However, from a clinical standpoint, the increment in the prognostic information was not as great as we expected and one may consider that indexed and non-indexed values of peak oxygen consumption have roughly similar prognostic value. This may in part be due to the fact that our population lacked very young or very old patients, who do not often have heart failure or who are less often exercised, respectively.

Another issue that we sought to address was whether the peak oxygen pulse was a better predictor of outcome than peak oxygen consumption, an issue not previously examined. Our hypothesis was that a large chronotropic reserve, due to young age or to previous training, may in theory compensate for a low stroke volume and maintain exercise cardiac output; it might thus be useful to eliminate the confounding role of heart rate by using the oxygen pulse, which is the product of stroke volume and arteriovenous oxygen difference. Surprisingly, our results showed that peak oxygen pulse had a low prognostic value. This suggests that heart failure is associated with a reduced chronotropic reserve during exercise ${ }^{28}$ (because of down regulation of atrial $\beta$ adrenergic receptors, ${ }^{29}$ altered kinetics of the sympathetic response, ${ }^{30}$ resting tachycardia, or simply because symptoms lead the patient to stop exercising before reaching the maximum predicted heart rate), which participates in the exercise limitation and perhaps carries its own prognostic value, as recently suggested from large epidemiological studies. ${ }^{31}$ Atrial fibrillation may also alter the predictive value of the peak oxygen pulse, but this does not seem to have been the case in the present study; however, the study does not have the power to address the question of whether peak oxygen pulse has a different predictive value in patients with atrial fibrillation because of the limited number of patients.

\section{CONCLUSIONS}

We found that peak oxygen consumption was the best predictor of vital outcome at long term in patients with heart failure, especially when indexed to predicted values. The peak oxygen pulse did not have prognostic value.

This work was supported by INSERM grant No 9110405 . 
1 The CONSENSUS Trial Study Group. Effects of enalapril on mortality in severe congestive heart failure. $N \mathrm{Engl} \mathcal{F}$

2 The SOLVD Investigators. Effect of enalapril on survival in patients with reduced left ejection fractions and congestive heart failure. N Engl F Med 1991;325:293-302.

3 Cohn JN, Johnson G, Ziesche S, Cobb F, Francis G, Tristani F, et al. A comparison of enalapril with hydralazine-isosorbide dinitrate in the treatment of chronic congestive heart failure. $N$ Engl f Med 1991;325:303-10.

4 Szlachcic J, Massie BM, Kramer BL, Topic N, Tubau J. Correlates and prognostic implication of exercise capacity in chronic

5 Cohn JN, Archibald DG, Francis G, Ziesche S, Franciosa JA, Harston WE, et al. Veterans Administration Cooperative Study on Vasodilator Therapy of Heart Failure: influence of prerandomization variables on the reduction of mortality by treatment with hydralazine and isosorbide mortality by treatment with hydralazine and is
dinitrate. Circulation 1987;75(suppl IV):IV-49-54.

6 Cohn JN, Rector TS. Prognosis of congestive heart failure Cohn JN, Rector TS. Prognosis of congestive heart failure and predictors of mortality. Am f Cardiol 1988;62:25-30A. mortality in chronic congestive heart failure secondary to mortality in chronic congestive heart failure secondary to
idiopathic dilated or ischemic cardiomyopathy. $\mathrm{Am}$ idiopathic dilated or

8 Franciosa JA. Why patients with heart failure die: hemodynamic and functional determinants of survival. Circulation 1987;75(suppl IV):IV-20-7

9 Mancini DM, Eisen H, Kussmaul W, Mull R, Edmunds LH, Wilson JR. Value of peak exercise oxygen consumption for optimal timing of cardiac transplantation in ambulatory patients. Circulation 1991;83:778-86.

10 Parameshwar J, Keegan J, Sparrow J, Sutton GC, PooleWilson PA. Predictors of prognosis in severe heart failure. Am Heart $\mathcal{F}$ 1992;123:421-6.

11 van den Broek SAJ, van Veldhuisen DJ, de Graeff PA, Landsman MLJ, Hillege H, Lie KI. Comparison between New York Heart Association classification and peak oxygen New York Heart Association classification and peak oxygen consumption in the assessment of functional status and prognosis in patients with mild to moderate chronic
congestive heart failure secondary to either ischemic or idicongestive heart failure secondary to either ischemic or idiopathic

12 Roul G, Moulichon ME, Bareiss P, Germain PH, Sacrez J, Mossard JM, et al. Exercise peak $\mathrm{VO}_{2}$ determination in chronic heart failure: is it still of value? Eur Heart $\mathcal{f}$ 1994;15:495-502.

13 Mudge GH, Goldstein S, Addonizio LJ, Caplan A, Mancini D, Levine TB, et al. Bethesda Conference: Cardiac Transplantation. F Am Coll Cardiol 1993;22:21-31.

14 Weber KT, Kinasewitz GT, Janicki JS, Fishman AP. Oxygen utilisation and ventilation during exercise in patients with chronic cardiac failure. Circulation 1982;65:1213-23.

15 Aaronson KD, Mancini DM. Is percentage of predicted maximal exercise oxygen consumption a better predictor of survival than peak exercise oxygen consumption for patients with severe heart failure? f Heart Lung Transplant patients with se

16 Stelken AM, Younis LT, Jennison SH, Miller DD, Miller LW, Shaw LJ, et al. Prognostic value of cardiopulmonary exercise testing using percent achieved of predicted peak oxygen uptake for patients with ischemic and dilated oxygen uptake for patients with ischemic and dila
cardiomyopathy. F Am Coll Cardiol 1996;27:345-52.

17 Cohen-Solal A, Benessiano J, Himbert D, Paillole C, Gourgon R. Ventilatory threshold during exercise in patients with mild to moderate chronic heart failure: determination, relation with lactate threshold and reproducibility. Int $\mathcal{f}$ Cardiol 1991;30:321-7.

18 Wasserman K, Hansen JE, Sue DY, Whipp BJ. Normal values. In: Wasserman K, Hansen J, Sue D, Whipp B, eds. Principles of exercise testing and interpretation. Philadelphia: Lea and Febiger, 1987:72-85.

19 Braunwald E. The history of heart disease. In: Braunwald E, ed. Heart disease: a textbook of cardiovascular medicine. Philadelphia: WB Saunders, 1984:12.

20 Kaplan EL, Meier A. Non-parametric estimation for incomplete observations. $\mathcal{f}$ Am Stat Assoc 1958;53:457-81. 21 Cox DR. Regression methods and life tables. $\mathscr{f} R$ Stat Soc 1972;B34:187-220.

22 Stevenson LW, Steimle AE, Fonarow G, Kermani M, Kermani D, Hamilton MA, et al. Improvement in exercise capacity of candidates awaiting heart transplantation. $\mathcal{F} \mathrm{Am}$ Coll Cardiol 1995;25:163-70.

23 Cohn JN, Johnson G, Shabetai R, Loeb H, Tristani F, Rector $\mathrm{T}$, et al. Ejection fraction, peak oxygen consumption, cardio-thoracic ratio, ventricular arrhythmias, and plasma norepinephrine as determinants of prognosis in heart norepinephrine as determinants of prognosis
failure. Circulation 1993;87(suppl VI):VI-5-16.

24 Di Salvo TG, Mathier M, Semigran MJ, Dec GW. Preserved right ventricular ejection fraction predicts exercise capacity and survival in advanced heart failure. $\mathcal{F} \mathrm{Am}$ Coll Cardiol 1995;25:1143-53.

25 Stevenson LW. Role of exercise testing in the evaluation of candidates for cardiac transplantation. In: Wasserman K, ed. Exercise gas exchange in heart disease. Philadelphia: Futura Publishing, 1996:271-86.

26 Cleland JGF, Dargie HJ, Fox I. Mortality in heart failure: clinical variables of prognostic value. Br Heart $\mathcal{F}$ 1987;58: 572-82.

27 Jones NL, Makrides L, Hitchcock C, McCartney N. Normal standards for an incremental progressive cycle Normal standards for an incremental progressive
ergometer test. Am Rev Respir Dis 1985;131:700-8.

28 Colucci WS, Ribeiro JP, Rocco MB, Quigg RJ, Creager MA, Marsh JD, et al. Impaired chronotropic response to exercise in patients with congestive heart failure. Circulation 1989;80:314-23.

29 Bristow MR, Ginsburg R, Ulmans V, Fowler M, Minobe W, Rasmussen $\mathrm{R}$, et al. $\beta 1$ and $\beta 2$ adrenergic-receptor subpopulations in nonfailing and failing human ventricular myocardium: coupling of both receptor subtypes to muscle contraction and selective $\beta 1$-receptor down-regulation in heart failure. Circ Res 1986;59:297-309.

30 Francis GS, Goldsmith SR, Ziesche S, Nakajima H, Cohn JN. Relative attenuation of sympathetic drive during exercise in patients with heart failure. $7 \mathrm{Am}$ Coll Cardiol 1985;5:832-9.

31 Lauer MS, Okin PM, Larson MG, Evans JC, Levy D. Impaired heart rate response to graded exercise: prognostic implications of chronotropic incompetence in the Framingham Heart Study. Circulation 1996;93:1520-6. 